\title{
EL FMLN Y LAS MEMORIAS DE LA GUERRA CIVIL SALVADOREÑA
}

\author{
Carlos Gregorio López Bernal*
}

Resumen: Este artículo estudia la construcción de las memorias de la guerra civil salvadoreña (1981-1992) desde una perspectiva histórica. Se propone que la guerra es recordada desde la especificidad de la experiencia de los diferentes actores de izquierda, lo cual da lugar a múltiples memorias, de las cuales se dan algunos ejemplos. Las memorias de la guerra civil no pueden entenderse si no se consideran las experiencias de organización y lucha de la década de 1970, que han sido absorbidas por la memoria oficial del Frente Farabundo Martí para la Liberación Nacional (FMLN), hoy en día partido político. Al apropiarse de esas memorias, el FMLN hace un uso político del pasado en función de su proyecto político actual que dista mucho del proyecto revolucionario.

Palabras clave: memoria colectiva; guerra civil; movimiento revolucionario; izquierda; Frente Farabundo Martí para la Liberación Nacional (FMLN); historia; El Salvador.

Abstract: This article studies the construction of thememories of the Salvadoran civil war (1981-1992) from a historical perspective. It is proposed that war is remembered from the specificity of the experience of the different leftist actors,

Fecha de recepción: 01/06/2017-Fecha de aceptación: 01/07/2017

* Salvadoreño. Doctor en Historia por la Universidad de Costa Rica (UCR). Docente e investigador de la Licenciatura en Historia, Universidad de El Salvador (UES). Correo electrónico: cglopezb@gmail.com 
which gives rise to multiple memories, of which some examples are given. It is not possible to understand the memories of the civil war without considering the experiences of organization and struggle of the 1970s, which have been absorbed by the official memory of the Farabundo Martí National Liberation Front (FMLN), now political party. By appropriating these memories, the FMLN makes a political use of the past in terms of its current political project that is far from the revolutionary project.

Keywords: Collective Memory; Civil War; Revolutionary Movements; Left; Farabundo Martí National Liberation Front (FMLN); History; El Salvador.

\section{Introducción}

Antes de la guerra civil, específicamente en las décadas de 1960 y 1970, la izquierda salvadoreña tuvo mucho interés en la historia del país porque en ella pretendió encontrar evidencias y argumentos que apoyaran, justificaran y orientaran sus luchas. Se constituyó un competente y muy diverso grupo de intelectuales que desde las ciencias sociales y la historia dieron sustento al proyecto revolucionario. Este esfuerzo de investigación, análisis y reflexión decayó una vez que inició el conflicto bélico y no se recuperó en la postguerra. Buena parte de la intelectualidad de izquierda se desvinculó del partido, a veces en condiciones muy conflictivas, mientras que el Frente Farabundo Martí para la Liberación Nacional (FMLN) dedicó su mayor energía al activismo político-electoral, dejando de lado la investigación y reflexión sobre la realidad del país.

Los trabajos de investigación histórica fueron desplazados por las memorias y los testimonios publicados por militantes y simpatizantes. Se entienden como memorias las narrativas escritas por la misma persona que vivió los hechos que narra y que, en general, tiene los medios para publicarlas. Los testimonios serían los relatos memoriales provenientes de personas de los sectores populares que no tienen posibilidad de publicar por su cuenta, y que narran la historia de su vida a otra persona que actúa como intermediaria y con la credibilidad y las posibilidades para publicarla en un formato determinado. ${ }^{1}$

La condición actual de quienes han publicado sus memorias y testimonios es muy diversa: algunos aún militan en el FMLN y siguen la línea del partido, otros dejaron la militancia partidaria, pero conservan una ideología de izquierda, y otros se han desvinculado del partido y la política. Son más numerosos los escritos de dirigentes, pero también se pueden encontrar otros

1 Véase, Erik Ching, Stories of Civil War in El Salvador. A Battle over Memory (Chapel Hill, EE. UU.: University of North Carolina Press, 2016). Introducción y capítulo 6. Este es el estudio más sistemático y completo sobre la memoria de la gerra civil salvadoreña. 
provenientes de mandos medios y militantes de base. Todos esos trabajos aportan insumos valiosos para el estudio de la historia del conflicto. Son "memorias autobiográficas" de los protagonistas, dan la versión y la visión de alguien directamente involucrado en el proceso. ${ }^{2}$

Asimismo, se han publicado testimonios de las víctimas de la represión gubernamental o sobre la experiencia de las comunidades organizadas en las zonas bajo control del FMLN. ${ }^{3}$ Pero también han comenzado a aparecer publicaciones que recogen testimonios de los abusos cometidos contra la población o sus propios militantes por la izquierda en armas. ${ }^{4}$ En menor medida también comienzan a publicarse testimonios y memorias desde la derecha. ${ }^{5}$ Además,

2 Por ejemplo: Eduardo Espinoza, Relatos de la guerra (San Salvador, El Salvador: Editorial Universitaria, 2007); Rodrigo Guerra y Guerra, Un golpe al amanecer (San Salvador, El Salvador: Índole Editores, 2009); Oscar Martínez Peñate, El Salvador, el soldado y la guerrillera: historia y relatos de vida (San Salvador, El Salvador: UFG Editores, 2008); Salvador Sánchez Cerén, Con sueños se escribe la vida: autobiografía de un revolucionario salvadoreño (México, D. F.: Océano Sur, 2008); Carlos Eduardo Rico Mira, En silencio tenía que ser: testimonio del conflicto armado en El Salvador (1967-2000) (San Salvador, El Salvador: Universidad Francisco Gavidia, 2003); José Luis Merino, Comandante Ramiro: revelaciones de un guerrillero y líder revolucionario salvadoreño (México D. F.: Oceano Sur, 2011); Francisco Mena Sandoval, Del ejército nacional al ejército guerrillero (San Salvador, El Salvador: Ediciones Arcoiris, 2006); Juan Ramón Medrano, Memorias de un guerrillero (San Salvador, El Salvador: New Graphic S.A. de C.V., 2006); Adolfo Majano, Una oportunidad perdida: 15 de octubre 1979 (San Salvador, El Salvador: Índole Editores, 2009); Nidia Díaz, Nunca estuve sola (San Salvador, El Salvador: UCA Editores, 1988); Carlos Consalvi Henríquez, La terquedad del izote. El Salvador, crónica de una victoria (San Salvador, El Salvador: MUPI, 1992); Lorena Peña, Retazos de mi vida. Testimonio de una revolucionaria salvadoreña (México, D.F.: Ocean Sur, 2009); Fermán Cienfuegos, Veredas de la audacia: historia del FMLN (San Salvador, El Salvador: Ediciones Roque Dalton, 1986).

3 Lou Keune, Sobrevivimos la guerra: la historia de los pobladores de Arcatao y de San José Las Flores (San Salvador, El Salvador: Adelina Editores, 1995); María López Vigil, Muerte y vida en Morazán: testimonio de un sacerdote (San Salvador, El Salvador: UCA Editores, 1987); Mario Alberto Pérez, José Aguirre Palacios y José Angel Portillo, Voces de Milingo (San Salvador, El Salvador: CEPAZ, 2002); María López Vigil, Don Lito de El Salvador: habla un campesino (San Salvador, El Salvador: UCA Editores, 1987); Jenny Pearce, Promised Land. Peasant Rebellion in Chalatenango, El Salvador (Londres, Inglaterra: Latin American Bureau, 1986); Francisco Metzi, Por los caminos de Chalatenango: con la salud en la mochila (San Salvador, El Salvador: UCA Editores, 1988); Lucio Vásquez, Siete gorriones (San Salvador, El Salvador: MUPI, 2012).

4 Geovani Galeas y Berne Ayala, Grandeza y miseria de una guerrilla (San Salvador, El Salvador: Centroamérica 21, 2008); Geovani Galeas, Héroes bajo sospecha. El lado oscuro de la guerra salvadoreña. Parte 1 (San Salvador, El Salvador: Athena Editores, 2013).

5 Mario Gómez-Zimmerman, El Salvador: la otra cara de la guerra (Miami, EE. UU.: Editorial SIBI, 1986); Geovani Galeas, "Mayor Roberto D’Abuisson: el rostro más allá del mito", La Prensa Gráfica, 7 de noviembre de 2004; Ricardo Orlando Valdivieso Oriani, Cruzando El Imposible: una saga (San Salvador, El Salvador: Imprenta Wilbot, 2008); René Obdulio 
existen numerosas iniciativas de estilo memorial en internet, las cuales escapan a los alcances de este trabajo. Este cúmulo de esfuerzos evidencian que la memoria sobre la guerra civil está en auge, lo cual es positivo en tanto que permite que los implicados en el conflicto den sus puntos de vista y reclamen por los agravios recibidos, sin olvidar que esta eclosión de memorias también implica prolongar la confrontación a una dimensión simbólica y de memorias en conflicto, en la cual recurrentemente se hace un uso político del pasado. ${ }^{6}$

Apoyándose en Maurice Halbwachs, Mauricio Menjívar concibe la "memoria histórica" como "una 'memoria prestada' de acontecimientos del pasado que el sujeto no ha experimentado personalmente y que se construye y modifica mediante lecturas, fotografías, videos u otro tipo de registros y se refuerza a través de las conmemoraciones". Para Menjívar, el adjetivo "prestada" es válido en tanto que existe una "memoria autobiográfica", que alude a eventos que se vivieron personalmente en el pasado. Aclara que esta memoria "tiende a desteñirse con el tiempo", a menos que sea periódicamente reforzada a través de la interacción con otras personas, que constituirían una "comunidad de memoria". ${ }^{8}$

Ese reforzamiento periódico de la memoria es asumido en la postguerra por actores sociales y políticos. Hay organizaciones no gubernamentales (en adelante ONGs) ligadas a la izquierda que trabajan sistemáticamente en el campo de lo que llaman "memoria histórica", y desarrollan un intenso trabajo de rememoración y conmemoración. Son ejemplos típicos de "emprendedores de memoria", es decir, personas o grupos que pretenden el reconocimiento social y la legitimidad de su versión del pasado y que trabajan por hacer visibles sus emprendimientos, entendidos como "su" verdad de los hechos acaecidos.

Flores Cruz, Memorias de un soldado (San Salvador, El Salvador: S/e, 2009); David Ernesto Panamá Sandoval, Los guerreros de la libertad (Andover, Massachusetts, EE. UU.: Versal Books, 2005).

6 Carlos Gregorio López Bernal, "Historia y memoria: los usos políticos del pasado", Revista Humanidades (El Salvador) V Época, 3 (enero-abril 2014): 13-19, URL: http://revistas.ues. edu.sv/index.php/humanidades/article/view/37.

7 Mauricio Menjívar Ochoa, "Los estudios sobre la memoria y los usos del pasado: Perspectivas teóricas y metodológicas", en: Historia y memoria: Perspectivas teóricas y metodológicas, Cuaderno de Ciencias Sociales No. 135, (ed.) Mauricio Menjívar Ochoa, Ricardo Argueta y Edgar Solano (San José, Costa Rica: FLACSO, febrero de 2005), 11, disponible en URL: http://www.flacso.or.cr/index.php/publicaciones-jb-br-jb-i-labor-editorial-jb-i/cuadernos/328-cuaderno-no-135.

8 Erik Ching prefiere hablar de "grupos de memoria". La distinción parece ser más bien operativa. En ambos casos se trata de compartir una experiencia y una visión interpretativa del pasado, articulada alrededor de memorias compartidas, que en algún momento terminan contraponiéndose con otras. Ching, Stories of Civil War...

9 Georgina Hernández Rivas, Cartografia de la memoria: actores, lugares y prácticas en El Salvador de posguerra (1992-2015) (Tesis Doctoral, Unversidad Autónoma de Madrid, 2015), 12. 
A menudo trabajan en coordinación con otras organizaciones y comunidades para conmemorar las efemérides que les interesan.

Debe señalarse que el repertorio de memorias de izquierda tiene soportes materiales muy diversos; desde el más tradicional — publicar memorias y testimonios impresos - , actividades públicas conmemorativas de eventos importantes en la guerra - acciones guerrilleras, masacres, repoblaciones, etc. -, documentales y producciones audiovisuales, hasta variados sitios en internet que contienen repositorios documentales, blogs y cuentas de Facebook. Incluso, proyectos aparentemente ligados a la reparación moral de las víctimas de violaciones de los derechos humanos, como un programa televisivo del gobierno llamado "Memoria viva", se prestan para hacer un uso político del pasado, en tanto que solo recoge las acciones represivas surgidas desde el Estado y la derecha, sin considerar la memoria de quienes pudieron haber sido afectados por acciones de la guerrilla. Obviamente, estas fueron menos numerosas, pero existieron; su omisión demuestra el sesgo de selectividad que caracteriza a las memorias.

Es decir, no todas las memorias tienen el mismo peso en el imaginario social; algunas se proyectan con mayor intensidad y adquieren gran resonancia; otras se dejan ver, pero sin llegar a tener un lugar preponderante, y quedan unas que difícilmente trascienden, ya sea porque sus portadores carecen de recursos para visibilizarlas o porque son bloqueadas debido a que muestran facetas del pasado que incomodan a grupos de poder.

\section{Los antecedentes inmediatos}

La década de 1970 vio una eclosión de organizaciones de izquierda. En esos años se conformaron cuatro de las cinco organizaciones político militares (en adelante OPM's) que más tarde conformarían el FMLN, pero también los frentes de masas vinculados a cada de una de ellas. Aunque tenían profundas diferencias, compartían el pensamiento marxista-leninista y la opción de la lucha armada como vía para la revolución. El Partido Comunista de El Salvador (PCS) existía desde 1930, pero solo optó por la lucha armada en $1979 .{ }^{10}$ Igualmente en esa década apareció una serie de organizaciones comprometidas con la lucha contra el régimen de derecha, pero con un pensamiento más cercano a la social democracia, que no apoyaban la lucha armada y tampoco pensaban

10 Un panorama de cómo surgen las OPM's salvadoreñas y sus principales rasgos aparece en Alberto Martín Álvarez, "De guerrilla a partido político: el Frente Farabundo Martí para la Liberación Nacional (FMLN)", Historia y Politica 25 (2011): 209-14, URL: https://recyt. fecyt.es/index.php/Hyp/article/view/41669. 
en la realización de una revolución socialista. Este último grupo terminó aglutinándose en el Frente Democrático Revolucionario (FDR).

La historia de la izquierda revolucionaria en la década de 1970 se caracteriza por la confrontación entre las OPM's. Aunque en cierta forma todas tienen sus raíces en el PCS, sus diferencias fueron tan grandes que en algunos casos dieron lugar a enfrentamientos que se saldaron con asesinatos. No obstante, la coyuntura que se abrió en 1979 con el triunfo de la Revolución Sandinista y el golpe de Estado contra el gobierno de Carlos Humberto Romero, hizo evidente la necesidad de unir fuerzas como única posibilidad de triunfo del proyecto revolucionario. El producto de este acuerdo fue la constitución del FMLN en octubre de 1980.

Los militares jóvenes que derrocaron a Romero en alianza con sectores civiles, incluidas ciertas organizaciones de izquierda, tenían claro que el país estaba al borde de la guerra civil y pretendían evitarla mediante la implementación de un programa de reformas largamente discutido y recurrentemente pospuesto. ${ }^{11}$ Sin embargo, la intransigencia y radicalidad de las extremas anularon políticamente el proyecto de reformas. La derecha estaba dispuesta a todo con tal de bloquear las reformas, primeras en la historia del siglo XX que afectaban realmente sus intereses económicos. Esas reformas eran parte de las demandas del movimiento social y de la izquierda, pero esta última las combatió porque le quitaban banderas de lucha y porque para entonces estaba empeñada en agudizar la confrontación con miras a provocar una insurrección popular como la ocurrida en Nicaragua.

Cuando el proyecto reformista se implementó fue combatido con igual denuedo por la izquierda revolucionaria y la derecha más conservadora. Para entonces el país ya estaba en plena guerra civil, lo que dio lugar a una abusiva injerencia estadounidense en la implementación de las reformas, especialmente la agraria, lo que aumentó las suspicacias sobre que las reformas eran contrainsurgentes. El FMLN libró una guerra por más de una década, experiencia clave en la conformación de las memorias de izquierda. Pero a diferencia de la década anterior, en la que la confrontación entre las OPM's fue abiertamente aceptada, para los ochenta se insistirá en la unidad, aunque la evidencia disponible deja ver que lo que se pregonaba como unidad era más bien una alianza de fuerzas diferentes que perseguían un objetivo común.

La firma de la paz en 1992 y la legalización del Frente como partido político permitieron la aparición de memorias de quienes militaron en la

11 La reforma agraria fue la más controversial de ellas, comenzó a discutirse a finales de la década de 1960, se volvió central después de la guerra con Honduras, pero fue tenazmente bloqueada por el capital a mediados de la década de 1970. En 1979, a la reforma agraria se añadió la nacionalización de la banca y del comercio exterior. Las tres tocaban los intereses económicos más importantes. 
izquierda, favorecida por las condiciones de libertad política del periodo, pero estimulada también por la necesidad de mostrar a la luz pública las experiencias del conflicto. Esas memorias reviven las vivencias, sufrimientos y traumas provocados por el conflicto; en cierto modo, trasladan al plano de lo simbólico la lucha que se había librado en los años anteriores.

La consolidación del FMLN como partido político legalmente constituido -hoy en el poder- y su ubicua presencia en la escena política y mediática oculta una compleja realidad histórica. En efecto, en El Salvador durante buena parte de la segunda mitad del siglo XX existió una diversidad de organizaciones de izquierda en diálogos e interacciones constantes, cuyos resultados no siempre fueron felices. En ese proceso de lucha hubo fuertes contradicciones que en ocasiones condujeron a la separación de un grupo de otra organización, en otras a la conformación de alianzas más o menos duraderas que dieron como resultado una paulatina redefinición de agendas y estrategias de luchas.

\section{Una periodización operativa}

Es pertinente proponer una periodización que dé sentido a la construcción de las memorias de las izquierdas en El Salvador, de cuya decantación se nutre la memoria del FMLN. Este no puede contener la rica experiencia de luchas políticas y sociales de las últimas décadas, no importa si se trata del periodo de formación de las OPM's, de la guerra civil o de la postguerra. Esta advertencia puede parecer innecesaria, sin embargo, adquiere sentido si se estudian los discursos de memoria del FMLN actual, el cual intenta monopolizar todo lo que esté relacionado con acciones de lucha política y popular.

Para el primer período, es más fácil establecer cuándo termina que su inicio. Engloba los sucesos previos a la conformación del FMLN (octubre de 1980) hasta la ofensiva general que marcó el comienzo pleno de la guerra civil en 1981. ${ }^{12}$ Este período comenzó en 1970, con la fundación de las Fuerzas Populares de Liberación (en adelante FPL); es decir, cubre la organización y primeros años de lucha de las OPM's, la fase de lucha de guerrilla urbana, su vinculación con otros sectores sociales y la conformación de sus frentes de masas, pero también la proyección de las OPM's hacia el campo. Dentro de

12 El FMLN se constituyó en 1980 con cinco organizaciones político-militares: Fuerzas Populares de Liberación Farabundo Martí (FPL), Ejército Revolucionario del Pueblo (ERP), Resistencia Nacional (RN), Partido Comunista de El Salvador (PCS) y Partido Revolucionario de los Trabajadores Centroamericanos (PRTC). Para una caracterización de cada una de las organizaciones, véase Alberto Martín Álvarez, De movimiento de liberación a partido político. Articulación de los fines organizativos en el FMLN salvadoreño (19801992) (Tesis Doctoral, Universidad Complutense de Madrid, 2004), 181-88. 
este arco temporal acaecieron otros hechos que también son importantes en la construcción de la memoria, como las experiencias de organización sindical ${ }^{13}$ y sobre todo campesina, la última muy ligada a la Teología de Liberación y las Comunidades Eclesiales de Base. ${ }^{14}$ Parte importante de la memoria del periodo es la represión gubernamental contra los movimientos sociales, ya sea en el marco de la lucha electoral o en acciones de protesta contra acciones del gobierno; tal fue el caso de la masacre de estudiantes en julio de 1975 o la protesta de febrero de 1977, luego del fraude en las elecciones presidenciales de ese año. También aparecen algunas masacres contra la población civil entre las que desataca la del Sumpul, en mayo de 1980 - y sobre todo operativos represivos contra campesinos organizados, especialmente en la región de Aguilares-Suchitoto y los departamentos de Usulután y Chalatenango. El último hecho significativo del período fue el asesinato de Monseñor Óscar Arnulfo Romero en marzo de 1980.

El segundo periodo abarcaría la guerra civil como tal, desde la "ofensiva general" de enero de 1981 a la firma del Acuerdo de Paz en enero de 1992. Obviamente este se centra en el enfrentamiento militar e incorpora algunas masacres perpetradas por el ejército, destacando especialmente la de "El Mozote" en diciembre de 1981. También incluye la llamada "ofensiva final" de noviembre de 1989. El ciclo se cierra con la fiesta de la paz, el 16 de enero de 1992. En el plano político-militar el gran protagonista es el FMLN.

Por último, habría que considerar el periodo de posguerra, que arrancando en 1992 se puede prolongar hasta la actualidad. En este caso destaca la desmovilización de la fuerza militar del FMLN, su conversión y legalización como partido político, y sus continuas participaciones en los procesos electorales de 1994 en adelante. Incluye la formal disolución de las diferentes OPM's que conformaron el FMLN, así como las sucesivas pugnas y divisiones que sufrió el partido hasta ser dominado por la facción ortodoxa, con la que ganó las elecciones presidenciales en 2009 y $2014 .{ }^{15}$

13 Una buena recopilación de la memoria del movimiento sindical aparece en Roberto Pineda, El Salvador: voces de la memoria rebelde. Entrevistas del Servicio Informativo Ecuménico y Popular (2004-2009) (San Salvador, El Salvador: Ediciones Prometeo Liberado, 2015).

14 Para un estudio del proceso, véase: Carlos R. Cabarrús, Génesis de una Revolución. Análisis del surgimiento y desarrollo de la organización campesina en El Salvador (México, D.F.: Ediciones de la Casa Chata, 1983); y Rodolfo Cardenal, Historia de una esperanza: vida de Rutilio Grande (San Salvador, El Salvador: UCA Editores, 2002). Para conocer la memoria de esos procesos son útiles, José Inocencio Alas, Iglesia, tierra y lucha campesina: Suchitoto, El Salvador (1968-1977) (San Salvador, El Salvador: Asociación de Frailes Franciscanos, 2003); y López Vigil, Don Lito de El Salvador...

15 Carlos Gregorio López Bernal, "Schafick Jorge Handal y la 'unidad' del FMLN de postguerra: entre la memoria y la historia. El Salvador (1992-2015)”, Diálogos (Brasil) 20, n. 2 
El FMLN y las memorias de la guerra civil salvadoreña

\section{El despliegue de las memorias}

La memoria de la guerra civil es un agregado, no siempre armónico pero sí complementario, de diversas memorias elaboradas por diferentes actores que participaron en el proyecto revolucionario. Aluden a sucesos que adquieren su significado específico en la perspectiva particular del actor que rememora, pero que a la vez son portadoras de un significado general asociado a la guerra civil como un todo.

La guerra es evocada desde la experiencia o la memoria socialmente construida de los individuos o los grupos sociales. ${ }^{16}$ En el primer caso se parte de las vivencias de cada persona en la época del conflicto; en el segundo, de rememoraciones elaboradas desde el marco social e inducidas desde las acciones de los "emprendedores de memoria" - personas o grupos que pretenden el reconocimiento social y la legitimidad de su versión del pasado, y que trabajan por hacer visibles sus emprendimientos, entendidos como "su" verdad de los hechos acaecidos,$-{ }^{17}$ labor que se concreta en eventos específicos de alta capacidad de rememoración. La participación en tales eventos coadyuva a formar una comunidad de memoria, entendida como grupos que se constituyen por los recuerdos compartidos del pasado, los cuales reproducen a través de prácticas sociales, políticas y culturales. ${ }^{18}$

\section{Una tipología de las memorias}

Para entender mejor el repertorio de memorias de la guerra civil es útil intentar una tipología. En primer lugar puede hablarse de una "memoria martirial" que retoma a las víctimas de la represión militar, ya sean civiles o militantes de izquierda, no caídos en combate. Alude básicamente a hechos de represión ejecutados por los cuerpos de seguridad, los Escuadrones de la Muerte o el ejército, en circunstancias en que las víctimas estaban desarmadas, aunque hay casos en que también se aplica a guerrilleros que caen en combate ante fuerzas muy superiores. En este caso se combina una construcción martirial de la memoria con otra memoria de carácter heroico, que estuvo muy en boga en la época del conflicto militar, justamente para crear figuras modélicas a imitar por parte de los combatientes y militantes de la izquierda en armas.

(2016): 13-29, URL: http://www.redalyc.org/articulo.oa?id=305549078003.

16 Maurice Halbawachs, Les cadres sociaux de la mémoire (Paris, Francia: Albin Michel, 1994).

17 Hernández Rivas, Cartografía de la memoria ..., 12.

18 Ibid, 145. 
La memoria martirial es muy importante en la conmemoración de masacres contra la población civil, por ejemplo El Sumpul y El Mozote (las más importantes), u otras de menor envergadura: El Calabozo, Las Hojas, etc. En estos relatos se destaca principalmente: la indefensión de las víctimas y la brutalidad de la represión (asesinatos, torturas, violaciones, mutilaciones, etc.). En el libro "Las mil y una historias de Radio Venceremos", se recoge el testimonio de un sobreviviente de la masacre de El Mozote:

"A los hombres los habían matado aparte, uno a uno. A las mujeres se las llevaban juntas y las mataban en montón. A las más bonitas las arrastraban a los matorrales, las violaban los soldados y luego las mataban degolladas y las traían a juntarlas con los demás muertos. No les importaba que fuera un anciano o una embarazada, todos eran parejos para morir. A los niños chiquitillos los tiraban para arriba y ponían el cuchillo del fusil para que cayeran trabados. Y a las viejitas las dejaron ahorcadas, colgando de los palos". ${ }^{19}$

Obviamente la versión de este libro es muy sesgada contra los militares. Mark Danner da una versión mucho más equilibrada en la que contrasta diferentes fuentes, sin embargo, la brutalidad de la matanza resulta igual en este texto. Queda bien clara la premeditación y alevosía con que el batallón Atlacatl actuó en contra de los civiles de El Mozote, por ejemplo, sacar a la gente de sus casas, tenerlas mucho tiempo tiradas de bruces en la calle y luego encerrarlas por la noche en el templo y algunas casas, para asesinarlas al día siguiente. ${ }^{20}$

La brutalidad y alevosía con que los victimarios actuaban es un rasgo recurrente en las memorias y testimonios de los años ochenta, pero también en los que se han recopilado posteriormente, lo cual demuestra el trauma que causaron. Una sobreviviente de la masacre del río Sumpul relata: "A una muchacha, aquí por el caserío El Rincón, la mataron. Ella era hermana de mi tía, ella estaba embarazada, la mataron, le sacaron el niño, y se lo dieron a los perros, la llevaron por el río, la violaron, después la quemaron". ${ }^{21}$

19 Testimonio de un sobreviviente de la masacre del Mozote, recogido en José Ignacio López Vigil, Las mil y una historias de Radio Venceremos (San Salvador, El Salvador: UCA Editores, 1991), 156-57.

20 Mark Danner, The massacre at El Mozote (New York, EE. UU.: Vintage Books, 1994), 62-74.

21 Testimonio de una participante en un taller de cartografía participativa, Arcatao, Chalatenango, El Salvador, abril de 2015. En Hernández Rivas, Cartografia de la memoria ..., 154. Narrativas similares aparecen en los testimonios recogidos por la Universidad Centroame- 
La magnitud de algunas masacres y la proyección que han tenido en los medios han hecho que alcancen un significado nacional, tales serían los casos de El Mozote y Sumpul; otras solo se conmemoran a nivel local y anclan la memoria de la guerra en espacios territoriales reducidos, por ejemplo, Gualcinga, El Calabozo, Las Hojas y otras. ${ }^{22}$

El 30 de julio de 1975 fue reprimida una manifestación de estudiantes universitarios y de secundaria en San Salvador. De esa masacre se destaca el carácter pacífico de la protesta que fue violentamente reprimida por los cuerpos de seguridad. ${ }^{23}$ Este evento tiene dos significados complementarios. Por una parte es un referente en la construcción de la memoria estudiantil, por haber sido las víctimas. De allí que sea una efeméride obligada en la Universidad de El Salvador, que con el correr del tiempo ha adquirido un ritual propio: desfile universitario a la hora en que sucedió en 1975, con comparsas que recrean el suceso y por la noche una especie de vigilia conmemorativa. Ricardo Argueta ha estudiado la construcción de la memoria de esta masacre y muestra cuánto difieren las versiones de los implicados — gobierno, estudiantes y testigos — y sobre todo, cómo los énfasis de la memoria han ido cambiando con el correr del tiempo. ${ }^{24}$ Por otro lado, en las memorias de algunos excombatientes del FMLN esa fecha marca un giro en

ricana “José Simeón Cañas”, en URL: https://www.youtube.com/user/AudiovisualesUCA. Especialmente la sección "Conflicto armado y Acuerdos de paz".

22 Vale decir que el término "masacre" se usa de manera bastante laxa entre los emprendedores de memoria; por ejemplo, el Equipo Maíz, ha registrado 227 masacres que van desde las más grandes ya reconocidas -El Mozote, que redondean a 1.000 víctimas-, a otras de solo 4 víctimas, que en realidad cayeron en enfrentamiento con autoridades. En otro caso, se registran aproximadamente 280 víctimas de la Guardia Nacional en el municipio de Intipucá, departamento de La Unión, pero en un lapso de tiempo de tres años, 1979-1981. "Listado de masacres en base a fuente Mapa masacres y conmemoraciones, elaborado por Equipo Maíz en el año 2005”, en: Ibid, 327-360.

23 Rufino Quezada Sánchez y Hugo Martínez, 25 años de estudio y lucha (Una cronología del movimiento estudiantil) (San Salvador, El Salvador: Editorial Universitaria, 2008), 49-52, disponible en URL: www.ues.edu.sv/descargas/25_aos_de_estudio_y_lucha.pdf. El testimonio de un sobreviviente aparece en Francisco Eliseo Ortiz Ruiz, De la memoria a la Historia: un acercamiento a la identidad de la Organización Política Resistencia Nacional (San Salvador, El Salvador: Instituto de Estudios Históricos, Universidad de El Salvador, 2014), 30-31.

24 Véase Ricardo Antonio Argueta, "La masacre del 30 de julio de 1975 en la memoria de los estudiantes de la Universidad de El Salvador", en: Historia y memoria: Perspectivas teóricas y metodológicas, Cuaderno de Ciencias Sociales No. 135, (ed.) Mauricio Menjívar Ochoa, Ricardo Argueta y Edgar Solano (San José, Costa Rica: FLACSO, febrero de 2005), 11. En los últimos años la vigilia prácticamente ha degenerado en fiesta y tiene poco de conmemorativa; tiende cada vez más a espacio de sociabilidad, al menos para los jóvenes estudiantes es un pretexto para una noche fuera de casa. 
sus vidas, eran estudiantes organizados y optaron por la lucha armada después de la masacre, cuya brutalidad los convenció de que la única manera de lograr cambios en el país era por la vía armada.

En la memoria de la masacre del 28 de febrero de 1977 prima el contenido cívico, ya que la protesta era contra el fraude en las elecciones presidenciales. Al igual que en las elecciones de 1972, la Unión Nacional Opositora (UNO) contó con el favor de los votantes, pero los resultados oficiales dieron el triunfo al Partido de Conciliación Nacional (PCN). Como respuesta, simpatizantes de la UNO se tomaron la Plaza Libertad, de donde fueron expulsados por las fuerzas de seguridad, dejando un saldo de decenas de muertos. ${ }^{25}$ Esta acción represiva fue una especie de confirmación extrema de que la apertura política que había vivido el país desde la década de 1960 se cerraba definitivamente. Quienes hasta entonces habían creído en la vía electoral como una posibilidad real para que la oposición tomara el poder fueron brutalmente reprimidos. Como sucedió en 1975 con la masacre estudiantil, hubo quienes vieron en el 77 un parte aguas en la historia de sus vidas y del país.

El último evento previo a la guerra civil con repercusión memorial importante es el asesinato de Monseñor Óscar Arnulfo Romero y la matanza que se dio en su sepelio. Desde mediados de la década los católicos organizados venían sufriendo una espiral de represión, incluso varios sacerdotes habían sido asesinados, pero que la derecha atentara contra el máximo jerarca eclesiástico fue algo inaudito para muchos. El asesinato del arzobispo, que se dio en el momento más importante del ritual católico, mostró claramente hasta dónde la derecha estaba dispuesta a llegar en su lucha contra el movimiento popular revolucionario: matar a Romero era decir "estamos dispuestos a matar a quién sea". Esta actitud se confirmó con la matanza en la Catedral el día del sepelio. Es frecuente que las memorias de excombatientes y militantes del FMLN, especialmente campesinos y obreros organizados en las Comunidades Eclesiales de Base, presenten el asesinato de Romero como el hecho que los impulsó definitivamente a la lucha armada.

En resumen, hay eventos previos a la guerra civil que tienen un alto contenido de memoria. Vistos en retrospectiva, algunos de ellos parecen haber definido el curso de los hechos, tanto para las personas que los vivieron, como para las organizaciones de izquierda y el país mismo. Prima la idea de que ciertos hechos tuvieron un efecto de demostración y convencimiento de

25 Véase Knut Walter Franklin, "Heridos por la historia: La retórica de la intransigencia (1972-1979)", en: El Salvador. La república, (ed.) Alvaro Magaña (San Salvador, El Salvador: Fomento Cultural Banco Agrícola, 2001). Tanto impacto tuvo esta acción represiva que poco tiempo después se organizaron las "Ligas Populares 28 de febrero" (LP-28), que fue el frente de masas del Ejército Revolucionario del Pueblo (ERP). 
que las vías tradicionales de organización y de disputa del poder se agotaban, y que solo quedaba el recurso de las armas para lograr los cambios.

La "memoria heroica" hace referencia a acciones de combatientes de la guerrilla que se distinguieron por su valor en combate, su audacia y su disposición al sacrificio por la causa revolucionaria. En el caso de guerrilleros caídos en combate, generalmente se trata de acciones de guerrilla urbana, células guerrilleras que fueron sorprendidas por la policía en "casas de seguridad" y que se resistieron a ser capturadas, dando prolongados combates ante fuerzas muy superiores que mataron a los rebeldes; en algunos casos los guerrilleros se suicidaron para no caer en manos del enemigo. Estos combatientes reciben simultáneamente los atributos de mártires y héroes. Este tipo de acciones corresponden principalmente al periodo de lucha de guerrillas urbanas, antes de la conformación del FMLN; es decir aluden a un periodo cuando cada OPM luchaba por su cuenta, por lo tanto, tienen mayor significado a nivel de una organización en particular y no del FMLN como tal. La lucha por separado de cada OPM es el rasgo que distingue a esta fase de lucha de la guerra civil propiamente dicha.

La narrativa de Lorena Peña sobre la muerte de su hermano, Felipe Peña, el 16 de agosto de 1976, deja ver la manera cómo se construye la memoria martirial. Lorena escribe: "Mi hermano fue asesinado, cayó en combate". La oración hace referencia al hecho con dos connotaciones distintas. La más cercana a lo acontecido es la segunda; el local que ocupaba Felipe Peña fue asaltado por la policía y en el combate murieron él y su esposa Gloria Palacios. Sin embargo, para su hermana, Felipe fue asesinado. Su muerte en combate lo convierte en héroe; el asesinato en mártir. ${ }^{26}$ Esos episodios están cargados de dramatismo. El 11 de octubre de ese mismo año la policía asaltó el local de una célula de las FPL; al darse cuenta de que no podían escapar los guerrilleros quemaron la documentación que podía comprometer a otros y trabaron un prolongado enfrentamiento en el que murieron los tres miembros de la célula. "Toño escribió FPL con su sangre en la pared y de la ele salía el hilo de sangre hasta donde quedó su mano tendida". ${ }^{27}$

La tónica de la memoria heroica cambia una vez que se conforma el FMLN y los enfrentamientos pasan a otro nivel en el marco de la guerra civil propiamente dicha. Van a destacarse principalmente acciones militares extraordinarias y determinantes para el curso de la lucha armada. Aunque hay casos en que se retoman acciones previas a 1980, en general se destacan

26 Peña, Retazos de mi vida ..., 61.

$27 \mathrm{Ibid}, 70$. 
eventos que se dan cuando el FMLN ya se ha constituido, y sobre todo cuando ha alcanzado una considerable capacidad militar. Muy importantes en este repertorio son la "ofensiva general" de enero de 1981, la "ofensiva final" en noviembre de 1989 y algunas campañas o acciones militares importantes, casi siempre ligadas a una OPM, por ejemplo la batalla del Moscarrón en Morazán, la campaña Comandante Gonzalo y los ataques contra la IV brigada en Chalatenango que terminaron en la "toma" del cuartel. En estos casos se resalta el heró́smo y la capacidad militar de las fuerzas guerrilleras, especialmente la Brigada Rafael Arce Zablah (BRAZ), que fue una unidad de élite del ERP, y las Unidades de Vanguardia (UV) de las FPL. ${ }^{28}$

La manera cómo las operaciones militares fueran proyectadas hacia afuera de los frentes de guerra dependía de la capacidad propagandística de cada OPM. En este campo destacó mucho el ERP, cuya zona de control era el noreste del país, especialmente los departamentos de Morazán y Usulután. La dirigencia del ERP dio mucha importancia al trabajo de propaganda y montó tempranamente la "Radio Venceremos" que después se transformó en Sistema Venceremos, que aglutinaba radio, prensa y cine. Por supuesto que estos instrumentos de propaganda revolucionaria hacían buen eco de los éxitos militares del ERP. Por ejemplo, el libro "Las mil y una historias de Radio Venceremos", recoge las crónicas de las operaciones militares más emblemáticas del ERP, en las que la BRAZ es principal protagonista. La batalla del Moscarrón en la cual el ERP dijo haber aniquilado una compañía del ejército, se dio en el marco de la Campaña Comandante Gonzalo en junio de 1982. Esta fue transmitida por la Venceremos, "como el reportaje era en vivo, desde el mero frente de guerra, salía al aire todo el tiroteo, los helicópteros, el ruido de los aviones A-37, el ruido de los bombazos... Fue una victoria estrepitosa. El enemigo tuvo más de doscientas bajas, un muerterío horrible". ${ }^{29}$

Por su parte, las FPL, que eran fuertes en Chalatenango, destacan los ataques contra la IV brigada de infantería y la presas hidroeléctricas del río Lempa. Obviamente en esas acciones participaron fuerzas provenientes de las otras OPM's, pero el grueso de combatientes provenía de las FPL. ${ }^{30} \mathrm{Al}$ igual que el ERP, las FPL dedicaron amplios esfuerzos al trabajo de comunicaciones

28 Las acciones de estas unidades guerrilleras han sido tema de numerosas publicaciones, en el caso de la BRAZ destaca Héctor Ángel Ibarra Chávez, Brigada Rafael Arce Zablah, ;misión cumplida!: una historia contada por sus protagonistas (México, D.F.: Ediciones Expediente Abierto, 2009).

29 López Vigil, Las mil y una historias..., 172.

30 La narración más detallada del ataque a la IV Brigada aparece para las UV de las FPL, véase: Armando Salazar, Los secretos del paraíso. Asalto a la cuarta brigada, Chalatenango (San Salvador, El Salvador: UCA Editores, 2016). 
y propaganda. Tan temprano como en 1974 ya tenían una Comisión Nacional de Propaganda (CONAPROP); uno de sus impresos, "El Rebelde", llegó a tener un tiraje de 20,000 ejemplares. Ya para 1980 fundan una agencia de prensa (SALPRESS) que funcionaba en México y daba cobertura al proceso revolucionario para el exterior, y que más tarde sirvió a todo el FMLN. ${ }^{31}$

Pero también hay memorias de acciones militares que exaltan la valentía de jefes y combatientes que a título individual definieron momentos clave de la lucha armada. Algunos de esos sucesos han sido publicados como testimonios, pero muchos otros permanecen en el repertorio oral de excombatientes y pobladores; son temas recurrentes de pláticas y tertulias que convocan por las tardes y noches a viejos y jóvenes en zonas de influencia del FMLN, por ejemplo, comunidades repobladas. En ellas y mediante ellas se mantiene viva y se reelabora la memoria social de la guerra civil en la base social de la izquierda salvadoreña.

La guerra es por naturaleza trágica, implica muerte, dolor y destrucción; sin embargo, ciertos eventos pueden adquirir una connotación festiva, en tanto marcan un punto de inflexión positivo o al menos un momento de pausa en el ajetreo bélico. Es lo que aquí se llama "memoria festiva". En las memorias de los combatientes son recurrentes las narraciones de las fiestas y bailes que se organizaban en los campamentos y zonas de control; mejor aún, las fiestas en las repoblaciones y por supuesto la celebración del Acuerdo de paz en 1992.

En medio de las acciones militares también había espacio para festejar. "Durante aquel año 83, la BRAZ llegaba y se tomaba un pueblo... Me acuerdo de una gran fiesta que armamos en San Fernando, como a finales de aquel año", relata un miembro de la Radio Venceremos. "Aquello parecía un carnaval. Los compas con los fusiles en medio de la gente, los niños saltando, las muchachas muriéndose por bailar con los combatientes de la BRAZ". ${ }^{32}$ Había fiestas incluso en los hospitales de la guerrilla, un espacio aparentemente muy poco propicio para este tipo de actividades. Delmy, una sanitaria de las FPL en Chalatenango, dice: "El área de sanidad se caracterizaba mucho porque le gustaban las fiestas. A veces, hasta en los hospitales hacíamos bailes, y los heridos, en los tapescos, bailando... Esas partes de la guerra fueron muy bonitas. A mí no me gusta la guerra, pero esas partes, las rescato". ${ }^{33}$ Un médico

31 Luis Alvarenga, La gramática de la pólvora. Los debates en la prensa revolucionaria salvadoreña (1971-1979) (San Salvador, El Salvador: UCA Editores, 2016), 57. Agradezco a Jasmín Cisneros López por los datos de SALPRESS.

32 López Vigil, Las mil y una historias..., 259.

33 FUNDABRIL, La otra cara de la guerra: salvar vidas (El Salvador: Talleres Gráficos UCA, 1012), 148. 
internacionalista relata en sus memorias esas fiestas en las que "era común ver bailar a compañeros con ojos, cabezas, brazos y aún piernas vendados. Vi bailar hasta a cutos con una sola muleta y una compañera". Añade que en las fiestas también se improvisaban "teatrillos" sobre la situación del país y la guerra, en la cual se aprovechaba para ridiculizar al enemigo. ${ }^{34}$

Diferente es el caso de las fiestas de las repoblaciones. En estas prima la alegría del retorno a la patria de los que estuvieron en los refugios, principalmente en Honduras. Estas festividades tienen un profundo significado para esas pequeñas comunidades. En primer lugar se destaca la lucha y la alegría de volver al país - que no significaba necesariamente volver al lugar de origen-, en todo caso se volvía a la patria todavía en guerra. Ciertamente que los refugiados deseaban volver al país, pero hoy se sabe que esos procesos no estuvieron desvinculados de la estrategia del FMLN previo a la ofensiva de 1989 y las negociaciones de paz. En una dinámica que todavía falta por conocer en detalle, miles de refugiados retornaron al país; la ubicación de las comunidades estuvo también condicionada a las necesidades del FMLN de reivindicar el control de territorios, asegurar rutas de abastecimiento y redefinir sus relaciones con su base social con miras a una paz negociada. ${ }^{35}$

Las fiestas de la repoblación marcan el calendario festivo de estas comunidades que, dependiendo del caso, se combinan con otras más tradicionales, por ejemplo la fiesta del santo patrono. Sin embargo, hay comunidades que se asentaron en territorios despoblados, a tal punto que la memoria local se ancla en la fecha de repoblación. La escogencia del nombre de la repoblación es un indicador del significado de la experiencia de la guerra. En algunos casos se regresa al municipio y el nombre se mantiene, por ejemplo, San José Las Flores, Arcatao o San Antonio Los Ranchos. En otros se vuelve a un lugar rural al que se le cambia el nombre; Guancora, un caserío en la jurisdicción del municipio de Chalatenango, pasó a llamarse "Ignacio Ellacuría", en honor a uno de los sacerdotes jesuitas asesinados en noviembre de 1989. Lo mismo sucedió con otras repoblaciones, por ejemplo, la comunidad "Segundo Montes" en Morazán, o la "Ángela Montano" en el bajo Lempa. La toponimia de las zonas de conflicto cambió considerablemente, de tal modo que la comunidad misma se volvió un referente identitario y de memoria.

34 Metzi, Por los caminos de Chalatenango..., 54.

35 Este es un tema que se ha explorado poco, pero los trabajos de Sprenkels comienzan a dar luz al respecto. Véase: Ralph Sprenkels, "Las relaciones urbano-rurales en la insurgencia salvadoreña", en: Historia y debates sobre el conflicto armado salvadoreño y sus secuelas, (ed.) Jorge Juárez Avila (San Salvador, El Salvador: Instituto de Estudios Históricos, Antropológicos y Arqueológicos /Fundación Friedrich Ebert, 2014), 36; y Ralph Sprenkels, Memoria, clandestinidad y censura: re-explorando la historia social de una repoblación (Ponencia presentada en el 55 Congreso Mundial de Americanistas, ICAS, San Salvador, 2015). 
Las fiestas de las repoblaciones son tan importantes que prácticamente son el equivalente a la fiesta patronal de otros municipios. "La celebración se acompaña con ferias de juegos mecánicos, la música de grupos locales, exposiciones, ciclos de cine documental o fotografías que recuerdan la vida en los campamentos de refugio y en las jornadas de retorno o la guerra civill". ${ }^{36}$ Estas celebraciones muestran una interesante mezcla de discursos memoriales; se celebra el retorno -que le da un marcado tono festivo a la celebració- pero el retorno no puede entenderse sin considerar el éxodo, es decir la huida, la persecución y la experiencia de los refugios, por lo tanto siempre hay espacio para la presentación de testimonios y "teatrillos" sobre las "guindas" y la vida de los refugios. Las diferencias generacionales de los participantes son evidentes, quienes vivieron en los refugios aún como niños, hoy son personas mayores que hacen esfuerzos por conservar la memoria y transmitirla a los más jóvenes, lo cual fatalmente implica adaptar ciertos elementos a los gustos y vivencias de las nuevas generaciones; por ejemplo, se hacen dos bailes: uno para los mayores, con música de la época de la guerra, y otro para los jóvenes, amenizado con una discoteca móvil. Lo importante es que estas comunidades parecen dispuestas a conservar su memoria de la guerra civil, esfuerzo en el cual a veces convergen con el FMLN y a veces marchan un tanto a contra corriente del partido.

La fiesta del Acuerdo de Paz, el 16 de enero de 1992, en el centro de San Salvador, fue algo memorable. El FMLN convocó a sus bases en la Plaza Barrios, mientras que el partido de derecha Alianza Republicana Nacionalista (ARENA) hizo la suya en la Plaza Libertad, a escasos cien metros de la otra. Los festejos iniciaron temprano en la tarde y se prolongaron hasta la madrugada. El FMLN movilizó a sus bases sociales desde el interior del país y con ellas llegó a San Salvador parte de sus combatientes. Las festividades transcurrieron sin incidentes, a pesar de los antecedentes de confrontación política. Fueron un buen augurio para el proceso de paz.

Todos los años se hace una conmemoración oficial, el 16 de enero. que corre por cuenta del gobierno en funciones. Sin embargo, con el correr del tiempo, esta festividad ha perdido brillo y significado. En primer lugar, porque la perenne confrontación entre el FMLN y ARENA boicotea la celebración. Mientras la derecha estuvo en el poder la izquierda hacía su propia celebración y no asistía a los actos oficiales; desde 2009 que el FMLN gobierna, la derecha no asiste. Independientemente de quién organice, hay poca participación de la población. Hay un cierto desencanto con los acuerdos de paz; hay quienes no perciben sus beneficios. Por otra parte, se asocia el creciente problema de la delincuencia y la violencia de las pandillas con la guerra, de tal modo que muchos consideran que no hay razones para celebrar.

36 Hernández Rivas, Cartografia de la memoria ..., 175. 
Todas las memorias discutidas arriba se afianzan en el recuerdo de la guerra civil, pero cada una de ellas se enfoca en un aspecto en particular del proceso y desde la óptica de un actor específico, ya sea a título individual o colectivo. La "memoria oficial" del FMLN tiene pretensiones más abarcadoras, esta se nutre preferentemente de la experiencia del Frente como tal en la guerra y la posguerra, pero se apropia de cualquier otra memoria del conflicto tanto como sea posible. El discurso de memoria del FMLN tiene un sentido teleológico en el que todas las experiencias de luchas libertarias previas conducen inexorablemente al proyecto revolucionario que fue liderado por el Frente.

En 2016 el FMLN publicó un libro muy interesante, mezcla indefinida de memoria e historia, con un título provocador y problemático: "35 años y adelante. Memorias para escribir el futuro". El título del libro sugeriría que se trata de una publicación más de corte memorial sobre la guerra civil, pero para el FMLN estas memorias serán la base para construir el futuro. El sentido teleológico del libro queda bien claro y se refuerza con las palabras introductorias de Medardo González: "La publicación de este libro constituye una merecida acción de rescate de la memoria popular y social del pueblo salvadoreño, de un imaginario colectivo que alumbrará la ruta de la verdad y el conocimiento a las nuevas generaciones." ${ }^{37}$ Pero las memorias contenidas en el libro también permitirían al lector conocer los orígenes y evolución del FMLN, y "acceder a la historia de nuestro país desde las voces de los campesinos, obreros, estudiantes, mujeres, sujetos todos excluidos en las historias oficiales escritas desde el poder oligárquico". ${ }^{38}$ Este libro bien puede ser el compendio de esa "memoria oficial" del FMLN en la que el pasado es puesto en función de un proyecto político del presente, usando indistintamente memoria e historia.

Mantener viva la memoria de la guerra civil es una preocupación de primer orden para el FMLN actual. De hecho, cuenta con organismos dedicados a este tipo de actividades; por ejemplo, la Secretaría de Memoria Histórica, encargada de las efemérides del Frente y de programas relacionados con la memoria, ${ }^{39}$ o el Instituto de Estudios Políticos "Schafik Jorge Handal", que pretende estudiar y divulgar el pensamiento político del líder. ${ }^{40}$ Desde

37 Medardo González y Nidia Díaz (eds.), 35 años y adelante. Memorias para escribir el futuro (San Salvador: Frente Farabundo Martí para la Liberación Nacional, 2016), 7.

$38 \mathrm{Ibid}$. El énfasis es mío.

39 Secretaría de Memoria Histórica FMLN, Documento conceptual sobre memoria histórica (San Salvador 2006).

40 Véase, URL: https://institutoschafikhandal.wordpress.com/. En enero de 2015 realizó el "Primer Seminario Internacional Vigencia del pensamiento de Schafick en la América Latina del siglo XXI"; un año después tuvo lugar la segunda edición. El sitio web contiene al 
esas instancias fluye un discurso que se ancla en el pasado para justificar el accionar político del presente; por lo tanto, su norte no proviene del pasado sino del presente, a este constructo se le denomina "memoria oficial". Son las coordenadas actuales del partido las que determinan la memoria, y esas coordenadas son, entre otras, la "unidad" del partido y su identidad revolucionaria. En ambos casos se recurre al pasado en busca de ejemplos y argumentos que coadyuven al proyecto político actual.

\section{Memoria, unidad e identidad en el FMLN}

La unidad es un elemento clave en todo partido, especialmente para uno como el FMLN, cuya conformación inicial en 1980 se hizo a partir de la alianza de cinco organizaciones político-militares que en la década anterior habían mantenido intensas disputas político-ideológicas. El Frente retomó el nombre de Farabundo Martí en busca de raíces históricas y de un sentido identitario que fuera compartido por todas las organizaciones. En realidad, el nombre de Martí fue reivindicado primeramente por las FPL, fundadas por Salvador Cayetano Carpio en 1970. Esa primera apropiación evidenciaba las profundas diferencias entre las FPL y el PCS. En efecto, las bases estatutarias de las FPL decían: "La figura de Agustín Farabundo Martí inspira a los combatientes revolucionarios actuales, en la lucha ideológica contra las posiciones seudorevolucionarias de los falsos comunistas que han abandonado la tradición combativa de nuestro pueblo y los principios y métodos en que sustentaron sus luchas Martí y la generación obrero-campesina de esos años" ${ }^{41}$ La alusión al PCS es clarísima.

El ERP surgió dos años después, obviamente difería con el PCS y las FPL, pero sus conflictos más fuertes fueron internos; a raíz de ellos se dio el asesinato del poeta Roque Dalton y de Armando Arteaga, dando como resultado la escisión de la Resistencia Nacional (RN) y en cierta forma del Partido Revolucionario de los Trabajadores Centroamericanos (PRTC). Sin embargo, las cinco organizaciones tenían fuertes disputas entre sí. Alvarenga señala que la década de 1970 "se caracterizó por un tremendo sectarismo y que estas organizaciones muchas veces pecaban de creerse dueñas de la verdad absoluta y de ser las únicas verdaderas revolucionarias". ${ }^{42}$ Este juicio es confirmado

menos 39 ponencias presentadas, la mayoría por altos dirigentes del partido, pero hay también de cubanos y de otros países. En todas se destaca el valor del ejemplo, el pensamiento y el legado de Handal para el partido.

41 Bases Estatutarias de las Fuerzas Populares de Liberación "Farabundo Martí", 1977. En http://www.ecumenico.org/article/bases-estatutarias-de-las-fuerzas-populares-de-lib/.

42 Alvarenga, La gramática de la pólvora ..., 50. 
gráficamente por José Luis Merino, dirigente del PCS: "En ese momento no existía ninguna comunicación ni coordinación con los otras cuatro organizaciones revolucionarias... Éramos diferentes. Más bien éramos enemigos. Para los otros hermanos, nosotros éramos los 'electoreros revisionistas', y ellos eran para nosotros los "ultraizquierdistas radicales". ${ }^{43}$

A excepción del PCS, las otras cuatro compartían la vía armada como camino a la revolución; con sus matices todas decían ser marxista-leninistas, pero diferían mucho sobre la estrategia de lucha, que iba desde enfoques insurreccionales hasta la guerra popular prolongada. Además, tenían simpatías o antipatías por otros modelos y procesos revolucionarios. Esas divergencias se materializaban en posicionamientos ante situaciones específicas, como las elecciones presidenciales, el análisis de una coyuntura y las acciones por tomar, las disidencias, algunas de las cuales terminaron en escisiones y asesinatos. En fin, en ocasiones parecía que las OPM's estaban más interesadas en disputar entre ellas que en combatir al gobierno. Oportunismo, electorerismo, izquierdismo, militarismo, voluntarismo, empirismo, exhibicionismo pequeño-burgués, son algunos de los epítetos que las OPM's se lanzaban para descalificarse. ${ }^{44}$

Sin embargo, la evolución de los procesos políticos en la región centroamericana y en el país, obligó a redefinir posicionamientos. El triunfo de los sandinistas en julio de 1979, y el proyecto de reformas surgido del golpe de Estado contra el presidente Romero en octubre de ese año, más la creciente combatividad de las organizaciones populares, crearon condiciones inéditas para la causa revolucionaria; aprovechar ese escenario solo sería posible si las OPM's se unían o al menos establecían una alianza funcional.

Lograr esa alianza requería limar asperezas acumuladas en casi una década de constantes contradicciones entre las organizaciones de izquierda y que el PCS virara hacia la lucha armada, lo que solo hizo en $1979 .{ }^{45}$ A mediados de ese año, Cayetano Carpio debió ir a Cuba para operarse de la vesícula, acompañado por Lorena Peña. Los cubanos le dieron una casa de playa para que convaleciera. Estando allí, le avisaron que tenía una visita; era

43 Merino, Comandante Ramiro..., 42. Esas disputas entre las OPM's se trasladaban a los frentes de masas o al campus de la Universidad de El Salvador, en donde todas las organizaciones hacían trabajo de organización y reclutamiento. Véase: Ortiz Ruiz, De la memoria a la Historia ..., 23-29.

44 Véase: Prensa Comunista, Órgano de prensa clandestino de la Resistencia Nacional, \# 30, octubre de 1977.

45 La opción por la lucha armada se impuso en el VII Congreso del PCS en abril de 1979, "surgió entre nosotros el concepto de partido en guerra, cuya idea central es hacer apto al partido para cumplir su misión en la guerra". Pero volver operativo ese acuerdo tomó su tiempo; las Fuerzas Armadas de Liberación (FAL) que se convirtieron en el brazo armado del partido se fundaron en marzo de 1980. 
Schafick Handal, a quien no había visto durante casi una década. Se saludaron fríamente y en un ambiente tenso Handal le dijo que el PCS estaba por incorporarse a la lucha armada. Peña dice que Carpio respondió: "Ya era tiempo que lo hubieran pensado", luego agregó: "Esa cosa es seria, a la guerrilla no se juega" ${ }^{46}$ En sus memorias, Handal agrega otros obstáculos que debió enfrentar el proceso, por ejemplo unos asesinatos de miembros del PCS que este atribuía al ERP y los recelos del ERP hacia la RN y el PRTC, organizaciones que habían surgido de su seno. ${ }^{47}$

El FMLN se fundó el 10 de octubre de 1980, con cuatro organizaciones; unos meses después de agregó el PRTC. La fundación del FMLN se hizo en un contexto de urgencia; por un lado la creciente represión contra el movimiento popular y la guerrilla, que incluyó el asesinato de Monseñor Romero, más el entusiasmo por el triunfo sandinista en Nicaragua, crearon un ambiente de radicalización en las masas que hacía prever altas posibilidades de triunfo para una insurrección liderada por el Frente. Los meses que siguieron al asesinato de Romero fueron los más adecuados para ejecutarla, pero el FMLN aún no existía. Se lanzó una "ofensiva general" en enero del 81, pero no hubo insurrección popular. El FMLN debió replegarse y comenzar a construir una retaguardia en el campo en una estrategia de guerra de más largo plazo.

En 1980, la posibilidad de la toma del poder por la izquierda radical, más la intervención cubana forzaron a un giro pragmático a las cinco OPM's que se aliaron para formar el FMLN, sin que por ello sus diferencias desaparezcan. A esta alianza se agregó el Frente Democrático Revolucionario (FDR) que trabajó el área político-diplomática. Esa coalición fue suficientemente eficaz para sostener la lucha por doce años, pero la guerra civil terminó en la mesa de negociaciones en 1992.

La firma de la paz conllevó a que el FMLN renunciara a la lucha armada como vía de acceso al poder, y en contraparte se permitió su legalización como partido político y además se implementaron una serie de reformas tendientes a la desmilitarización y a la democratización del país. El FMLN que se legaliza como partido político estaba compuesto por las cinco organizaciones político militares que se unieron para hacer la guerra revolucionaria. No obstante sus profundas diferencias, antes y durante el conflicto armado, tenían un objetivo aparentemente bien definido: "tomar el poder político y transformar la sociedad". ${ }^{48}$ Esto les permitió una aparente unidad.

46 Peña, Retazos de mi vida..., 82.

47 Schafik Jorge Handal, Legado de un revolucionario. Del rescate de la historia a la construcción del futuro (San Salvador, El Salvador: Instituto Schafick Handal, 2011), 243-44.

48 Merino, Comandante Ramiro..., 129. 
Pero las diferencias al interior del FMLN se hicieron públicas en la primera legislatura de la cual formó parte. A mediados de 1995, un grupo de la fracción legislativa del FMLN, correspondiente al ERP y la RN, votó a favor de una propuesta de la derechista ARENA para aumentar el Impuesto al Valor Agregado (IVA), acción denominada "Pacto de San Andrés" y que fue considerada como traición por el resto de la dirigencia del Frente. Poco tiempo después estos disidentes se separaron del FMLN y conformaron el Partido Demócrata, de efímera existencia. Este fue el inicio de una larga serie de disputas y disensiones al interior del Frente. ${ }^{49}$ Entre 2001 y 2004, y adicionales a las tradicionales afiliaciones de las cinco antiguas organizaciones guerrilleras, al interior del Frente coexistían al menos cuatro tendencias: la "Corriente Revolucionaria Socialista" (CRS) liderada por Handal y Sánchez Cerén -la más ortodoxa y radical-; el "Movimiento Renovador", cuyas cabezas más visibles eran Facundo Guardado y Francisco Jovel; la "Tendencia Revolucionaria", de pensamiento muy radical, pero sin expresión política organizada conducida por Dagoberto Gutiérrez, y los “terceristas", liderados por Gerson Martínez. ${ }^{50}$

Al final de un turbulento proceso de disputa por la conducción del partido, los llamados "ortodoxos", liderados por Shafick Handal (PCS) y Salvador Sánchez Cerén (FPL), coparon la dirección. Handal murió en 2006; tres años después el FMLN ganó las elecciones presidenciales llevando como candidato a Mauricio Funes, un periodista no militante a quién Handal bloqueó la candidatura presidencial en 2004 por considerar que no representaba ni defendería el proyecto revolucionario. En 2014 el Frente ganó de nuevo las elecciones presidenciales, esta vez postuló a dos comandantes históricos, Salvador Sánchez Cerén y Óscar Ortiz.

Esta breve revisión de la historia del FMLN demuestra que las diferencias, más que la unidad, han sido la constante. Un estudio más detallado mostraría además que esas diferencias son reflejo de la diversidad de pensamiento político que caracterizó a la izquierda salvadoreña en las décadas de 1970 y 80; quizá esa diversidad fue lo que le dio tanta creatividad y flexibilidad para enfrentar los retos del conflicto armado. Sin embargo, la historia también muestra que no siempre las izquierdas, y sobre todo el FMLN, han sabido procesar las diferencias; en varias ocasiones la intolerancia y el fanatismo han sobrepasado la voluntad de diálogo y entendimiento, a veces con resultados trágicos.

49 Véase, Álvaro Artiga González, "El FMLN. Entre la oposición y el gobierno tras doce años de elecciones", Revista Centroamericana de Ciencias Sociales (El Salvador) 3, n. 2 (2006): 58-59, URL: https://goo.gl/CCuUVM.

50 Sergio Arauz, "Sánchez Cerén rehabilita a los antiguos disidentes del FMLN", El Faro, 28 de abril de 2014, URL: http://www.elfaro.net/es/201404/noticias/15304/. 
Es entendible que el FMLN insista tanto en el tema de la unidad y niegue, oculte o simplemente ignore episodios que cuestionen esa unidad, que es reciente y que en todo caso se construyó sobre disputas, renuncias, expulsiones y la descalificación de pensamientos que cuestionaran la línea política ortodoxa que hoy predomina en el partido. Paradójicamente, esa "ortodoxia" y radicalismo son más bien discursivos e ideológicos, no pragmáticos. La "radicalidad" que la ortodoxia del FMLN pregona no se refleja en su forma de gobierno, que a lo sumo es tímidamente reformista. Es más, muy discretamente el FMLN se ha ido distanciando de la agenda de reivindicaciones que eran bandera de lucha cuando era oposición, por ejemplo, revertir la dolarización, avanzar en la modernización del sistema político, fortalecer la separación de los órganos de Estado, etcétera.

Solo en los años que siguieron a su conformación se hablaba tanto en el FMLN de unidad como hoy en día. En el primer caso, el discurso escondía que la unidad era algo frágil y reciente, que las OPM's habían formado una alianza política obligadas por la necesidad de impulsar el esfuerzo bélico con la intermediación y presión de Cuba. En el segundo caso la unidad es la de los que hoy hegemonizan el partido e implica la anulación de todo cuanto pueda impugnar al grupo en el poder; es, por lo tanto, una memoria muy selectiva que excluye todo aquello que atente contra la "unidad" presente, y por el contrario exalta todo lo que coincida con la visión de un FMLN unido, pragmático y eficaz en el quehacer político.

\section{Conclusiones}

La memoria de la guerra civil es demasiado importante como para dejar que fluya sin orden. Es necesario administrarla debidamente a fin de sacarle el mejor provecho. En primer lugar se debe considerar algo que a menudo se pasa por alto: la memoria conlleva el olvido; es decir, no se puede ni se debe recordar todo. Es preciso depurar la memoria, ya sea porque hay sucesos que se consideran más importantes que otros, o porque hay algunos que no conviene que se recuerden.

Lo primero que se debe tener en cuenta es considerar la evolución histórica de la izquierda -mejor dicho de las izquierdas-, a fin de no dejarse obnubilar por la actual hegemonía del FMLN, partido político en el poder. Efectivamente, desde finales de la década de 1960 y sobre todo en la década de 1970, en América Latina y El Salvador surgieron y convivieron diferentes movimientos y organizaciones que se decían de izquierda, y que ciertamente lo eran, pero que también tenían profundas y significativas diferencias entre sí; diferencias que en algunos casos llevaron a divisiones y enfrentamientos que se saldaron con sangre. La década de 1970 vio la eclosión de un variado y 
rico pensamiento de izquierdas en El Salvador, el cual por razones prácticas, hacia inicios de 1980, se decantó en dos grupos aliados: el FMLN, conformado en octubre de ese año por cinco organizaciones político militares y sus correspondientes frentes de masas, y el Frente Democrático Revolucionario que aglutinó a organizaciones en general de pensamiento social cristiano, opuestas al gobierno, pero sin adscribirse al pensamiento marxista leninista y la vía armada que primaba en el FMLN.

En función de lo anterior es preciso distinguir las memorias que corresponden al periodo previo a 1980, que hacen alusión particular a las diferentes organizaciones de izquierda entonces en boga; obviamente es una memoria escindida. Entre 1980 y el Acuerdo de Paz de 1992, la memoria se centra en el "FMLN histórico" y los hechos ligados a la guerra civil, predominan las masacres, los refugiados y los hechos militares. Paralelamente, pero muy reducida, subsiste la memoria propia de cada una de las OPM's que conformaban el FMLN. No obstante el importante papel político que jugó, el FDR se desdibuja y solo permanece como referente de memoria el asesinato de sus dirigentes en noviembre de 1980.

Después del Acuerdo de Paz, la memoria de las izquierdas pasa a un segundo plano y prevalece la del FMLN, partido político que intenta "acaparar" los méritos del proceso histórico; a su vez toma creciente importancia una memoria construida aparentemente desde la "sociedad civil". Pero esta a menudo es elaborada desde instancias en algún momento ligadas al FMLN; por ejemplo, la que se construye desde las ONGs y las comunidades en territorios que fueron base social del FMLN en la guerra.

Todas estas memorias tienen puntos en común, pero también manifiestan importantes diferencias y en ocasiones abiertos conflictos, el ejemplo más flagrante de lo último sería la memoria de los familiares y militantes víctimas de las purgas internas que realizó el comandante Mayo Sibrián en la zona paracentral, y el obstinado silencio de las FPL y el FMLN al respecto. ${ }^{51}$

Como bien apunta Elizabeth Jelin al discutir el concepto "memorias en disputa", estas no aluden únicamente a aquellas que registran las desavenencias entre bandos opuestos, también aplican a las diferentes visiones del pasado que existen dentro de un mismo grupo. ${ }^{52}$ Este despliegue de memorias cobija elaboraciones que pueden ser muy disímiles en su especificidad, y que no obstante convergen en algún punto con otra que se convierte en hegemónica. En el primer caso se está en presencia de la memoria particular de una

51 Véase, César Castro Fagoaga, "Mayo Sibrián, el carnicero de la Paracentral”, El Faro, 18 de septiembre de 2008, disponible en URL: http://mayosibrian.blogspot.com/2008/09/mayo-sibrin-el-carnicero-de-la.html; y Galeas y Ayala, Grandeza y miseria...

52 Elizabeth Jelin, Los trabajos de la memoria (Buenos Aires, Argentina: Siglo XXI, 2002). 
persona, de una comunidad que fue base histórica del FMLN, o de alguna organización o movimiento de los muchos que actuaron en las décadas de 1970 y 80; en el segundo caso estaríamos ante la memoria oficial del FMLN, partido político que hoy en día se arroga el derecho de hacer suyas memorias que remiten a un pasado de lucha o represión, pero que no siempre estarán en armonía con las acciones y pensamiento del FMLN como tal.

El acaparamiento y uso de ese "arsenal memorial" es posible por varios factores. En primer lugar, porque el FMLN es actualmente la principal fuerza de izquierda del país con estructuras organizativas en todo el territorio y gobierna el país desde 2009; en este sentido, tiene una amplia gama de recursos y una presencia mediática permanente. Maneja además una agenda de efemérides ligadas a las luchas populares en las que imprime su huella. Posee o marca la agenda de diferentes medios de comunicación -radio, televisión, prensa escrita e internetque amplían la resonancia de sus acciones, ya sea como gobierno o partido. El FMLN cuenta con instancias estrechamente vinculadas a él, por ejemplo "Radio Maya Visión", GENTEVÉ canal 29 y una variopinta cantidad de sitios en internet afines al partido. Se debe agregar que desde 2009, la radio y la televisión del Estado siguen la línea del FMLN, al punto que transmiten actividades de este.

Por otro lado, las facciones que se escindieron del FMLN en el marco de las pugnas internas posteriores al acuerdo de paz no pudieron constituirse en fuerzas políticas permanentes, por consiguiente, aunque hay eventos históricos que podrían reivindicar como suyos, no tienen la estructura organizativa necesaria para hacerlo. ${ }^{53}$ Por último, existe en el país una cantidad de ONGs y repoblaciones con condiciones para tener su propia agenda memorial, pero terminan cayendo en la esfera de influencia del FMLN debido a que mantienen vínculos orgánicos o de afinidad político ideológica con el partido. En resumen, el FMLN actual ha logrado absorber, desplazar o anular políticamente al amplio repertorio de organizaciones de izquierda que antes existieron, asimismo ha tratado de apropiarse de cualquier memoria que haga alusión a luchas políticas y sociales, con el fin de auto-representarse como heredero de ese legado histórico de luchas populares.

53 Quien se retira o es expulsado del FMLN, ipso facto renuncia también al sentido identitario del partido. Esta ha sido una regla tácita en todos los desmembramientos del FMLN de postguerra. Algunos de los que han salido del Frente han tratado de formar otras organizaciones -Partido Demócrata, Partido Social Cristiano, Frente Democrático Revolucionario, por nombrar algunos-, pero nadie ha pretendido apropiarse del nombre del FMLN. 